\title{
Editorial
}

\section{The Special Iranian Issue}

\section{Ulrika Mårtensson}

It is with great pleasure that I introduce this issue of Comparative Islamic Studies as a thematic one, edited by Milad Odabaei, and focusing on the topic "Iranian Cosmopolitanism."

The issue contains an Introduction, followed by four articles and four review essays. Initially, the idea behind it was inspired by Lucian Stone's recent edited volume on the same topic, Iranian cosmopolitanism, which Odabaei reviewed in this journal (issue 9.2, 2013 [2016]). Since Odabaei in his Introduction describes the frame and questions addressed in the collection, I will not expand on the contents here.

However, a few words can be said about why Iranian Cosmopolitanism is a topic for this journal devoted to comparative Islamic studies. Most obviously, the nation-state Iran is constitutionally an Islamic Republic, a topic reflected in several ways in the contributions, and the population is overwhelmingly Muslim. And of course, Islam also constitutes to a large extent the historical discourses treated in the collection, and as such has shaped ways of knowing "other" countries, religions and peoples. Yet, as is the case with Islam in general, "Iranian Islam" also encompasses such general disciplines and sciences as philosophy and ethics, statecraft and diplomacy, and history, and is expressed through literary genres and modern media. It relates to, for example, ways of conceptualizing and managing religious diversity, science and technology, and modern global popular culture, including political phenomena such as conspiracy theory. Though the collection withholds any simple answer to the question of what "Iranian Cosmopolitanism" might be, it thus highlights the varied significances of Islam for probing the topic. It also addresses the question of comparison, which is central to the journal, through this focus on distinct "ways of perceiving and knowing." In other words, by locating the study of Islam vis-à-vis the history of Iran and related literatures and media on the one hand, and general concepts, categories and disciplines

\section{eevunoxonlıne}


on the other, the volume contributes to comparative Islamic studies. In the same way, the collection makes an important contribution to studies of "cosmopolitanism," and indeed also to globalization studies and their critical reflection over relations between the global and the local, and claims to general validity for particular visions and practices.

I also want to thank all the contributors to this issue: Milad Odabaei for initiating and editing the collection and the authors for contributing with their articles; the anonymous reviewers for their careful readings and constructive comments; Russell Adams for production and editing; Ailsa Parkin for editorial assistance and guidance; and Janet Joyce for generous advice, and for the opportunity.

\section{eevunoxonline}

